\title{
Sideroblastic and megaloblastic change
}

\author{
W. E. BAgnALL \\ B.Sc., M.R.C.P.
}

\author{
M. J. FAIRMAN \\ M.B., M.R.C.P.
}

St James's (University) Hospital, Leeds

\section{Summary}

A case of primary sideroblastic anaemia is described in which megaloblastic changes in the bone marrow were found to be due to coincidental pernicious anaemia.

The importance is stressed of investigating all cases of macrocytic anaemia by iron staining of the marrow together with estimation of the serum $B_{12}$ and folate levels.

\section{Introduction}

THE simultaneous occurrence in the bone marrow of megaloblasts and ring-sideroblasts may result from a variety of causes. In a series of seventy patients with sideroblastic anaemia, MacGibbon and Mollin (1965) observed megaloblastic change in $54 \%$ of cases of primary sideroblastic anaemia, and in $74 \%$ of cases of secondary sideroblastic anaemia. The megaloblastic change was attributed to folate deficiency which they detected in $80 \%$ of both primary and secondary forms. A favourable response to folate therapy was evident in $40 \%$ of the patients. In pernicious anaemia, also, small numbers of ringsideroblasts are frequently demonstrated in the late megaloblasts although treatment with vitamin $\mathbf{B}_{12}$ results in their rapid disappearance.

A further cause of concurrent sideroblastic and megaloblastic change is illustrated by the following case.

\section{Case report}

A woman aged 75 years presented with a history of progressive fatigue, effort dyspnoea, palpitations and episodes of faintness during the previous 9 months, with the recent development of a sore tongue and mouth. There was no relevant family history. She had been treated by her general practitioner for some months with oral iron.

Investigations revealed a haemoglobin of $7.9 \mathrm{~g} / \mathrm{dl}$. MCV $130 \mathrm{fl}$; RBC $1.9 \times 10^{12} / 1$; WBC $3.6 \times 10^{9} / 1$ (normal differential). The blood film was macrocytic with hypersegmented neutrophils. Bone marrow aspiration showed greatly increased cellularity and

Correspondence: Dr M. J. Fairman, Department of Medicine, St James's Hospital, Leeds LS9 7TF. gross erythroid hyperplasia with a shift to the left. Development of the red cells was megaloblastic. Iron stains revealed ring-sideroblasts in virtually all early, intermediate and late red cell precursors. Serum iron was $32 \mu \mathrm{mol} / 1$; TIBC $60 \mu \mathrm{mol} / 1$; serum folate $4.3 \mu \mathrm{g} / \mathrm{l}$; red cell folate $62 \mu \mathrm{g} / \mathrm{l}$; serum $B_{12}$ $25 \mu \mathrm{g} / \mathrm{l}$; the Schilling test showed $6.1 \%$ excretion corrected to $23.7 \%$ with intrinsic factor; gastric parietal cell and intrinsic factor antibodies were present in the serum. A Diagnex Blue test showed presumptive evidence of achlorhydria. Barium meal showed mild gastro-oesophageal reflux and no evidence of carcinoma of the stomach. Treatment was started with vitamin $B_{12} 250 \mu \mathrm{g}$ i.m. thrice weekly for the first fortnight, resulting in a rise of haemoglobin from $7.9 \mathrm{~g} / \mathrm{dl}$ to $9.8 \mathrm{~g} / \mathrm{dl}$. The MCV fell to $114 \mathrm{fl}$ and the $\mathrm{RBC}$ rose to $2.5 \times 10^{12} / 1$, but at no stage did the reticulocyte count exceed $3.5 \%$. After 14 days of treatment with vitamin $B_{12}$ the marrow aspiration was repeated, showing typical appearances of primary sideroblastic anaemia. Erythropoiesis was predominantly normoblastic. Folic acid $15 \mathrm{mg}$ and pyridoxine $100 \mathrm{mg}$ daily were added, and during the next 5 weeks the haemoglobin continued to rise to $12 \mathrm{~g} / \mathrm{dl}$. The MCV fell to $98 \mathrm{fl}$, with a rise of the RBC count to $3.59 \times 10^{12} / 1$. A third marrow aspiration after 7 weeks of treatment showed changes typical of primary sideroblastic anaemia with abnormal ringsideroblasts in all stages of red cell precursor. She remains well at follow-up two years later.

\section{Discussion}

This case would appear to illustrate the coincidental occurrence of primary sideroblastic anaemia with pernicious anaemia.

Until relatively recently the classification of sideroblastic anaemia into primary and secondary types was based upon the simultaneous detection of other diseases. The observations of Hall and Losowsky (1966), however, enable such a classification to be made by examination of the bone marrow alone. Thus in primary sideroblastic anaemia ringsideroblasts are found in all stages of erythroblast maturation, whereas the early erythroblasts do not 
usually exhibit ring forms in the secondary or hereditary types.

From the initial marrow sample the diagnosis of primary sideroblastic anaemia was suggested by the presence of numerous ring-sideroblasts at all stages of erythrocyte maturation. At first the megaloblastic changes were attributed to folate deficiency, in association with primary sideroblastic anaemia. This opinion was revised at an early stage, however, in view of the Schilling test, serum $B_{12}$, and antibody results, which were characteristic of pernicious anaemia. The persistence of sideroblastic change in the marrow despite folate therapy and a response to vitamin $B_{12}$ suggested a concurrent primary sideroblastic anaemia.

The case illustrates the importance of investigating all cases of macrocytic anaemia by iron staining of the marrow together with estimation of the serum $B_{12}$ and folate levels. The possibility that megaloblastosis $\frac{2}{3}$ and sideroblastosis may be due to separate con- $\mathbb{\AA}$ ditions, as in this case, should be considered particu- $c$ larly when associated with a sub-optimal response to $\Rightarrow$ adequate $B_{12}$ replacement therepy.

\section{Acknowledgments}

We wish to thank Dr Eric Jackson for advice and per- $\frac{\bar{\omega}}{-}$ mission to publish details of the case, also Professor M. S. $\mathbb{\Phi}$ Losowsky and Roger Hall for their helpful criticism. Thanks also to Marion Stainthorpe and Mrs Brenda Day for secre-es tarial assistance.

\section{References}

Hall, R. \& Losowsky, M.S. (1966) The distribution of erythroblast iron in sideroblastic anaemias. British Journa of Haematology, 12, 334.

MACGibbon, B.H. \& Mollin, D.L. (1965) Sideroblasticior anaemia in man: observations on seventy cases. British Journal of Haematology, 11, 59.

\title{
Recurrent intussusception due to a primary colloid carcinoma of the large bowel in a child
}

\author{
M. A. TEHRANI \\ M.D., F.R.C.S. \\ Department of Surgery, Western Infirmary, Glasgow
}

\begin{abstract}
Summary
A case of recurrent colo-colic intussusception due to a primary colloid carcinoma of descending colon with widespread lymphatic involvement in a child, is reported. The unusual mode of presentation and lack of awareness were responsible for a delay of 6 months before the final diagnosis was made. Two years after the operation the patient is well and there is no evidence of clinically detectable secondaries.
\end{abstract}

\section{Introduction}

INTUSSUSCEPTION in adults has a predisposing mechanical cause in more than $50 \%$ of the patients (Donhauser and Kelly, 1950; Goodall, 1963) but in infants and children a demonstrable lesion, in particular a malignant tumour, is uncommon (Strang, 1959; Dennison and Shaker, 1970). The separation between these two groups of patients has been accepted as the adult patients being over 14 years of age (Goodall, 1963; Elebute and Adesola, 1964).

Correspondence: Mr M. A. Tehrani, Department of Surgery, Western Infirmary, Glasgow G11 6NT.
This report concerns a 12-year-old boy with recurrent colo-colic intussusception due to a primaryọ. mucoid carcinoma of the descending colon. The case is of interest because of the rarity of malignant $\mathrm{B}$. tumours of the colon in childhood and adolescencé and the unusual mode of its presentation.

\section{Case report}

A 12-year-old schoolboy was admitted to hospitap with the complaint of abdominal pain. His symptoms began 6 months before admission with intermitten? attacks of colicky lower abdominal pain and disten sion followed by diarrhoea and passage of blood and mucus per rectum. Between these attacks his generat health had been good and he had remained symptom $N$ free. Three weeks before admission, however, some weight loss and diminished appetite were noted byo his parents. He had never vomited but had nausea a times. There were no other symptoms or family? history of consequence.

On examination, he looked anaemic and appeared? tired but had no complaints. He was apyrexial and? normotensive. There were no abnormalities in $\vec{B}$ 